\title{
Analysis of anatomical variations of intrapelvic vessels for advanced pelvic surgery
}

\author{
Atsushi Hamabe, Takashi Harino, Takayuki Ogino, Tsukasa Tanida, Shingo Noura, Shunji Morita and Keizo Dono
}

\begin{abstract}
Background: In pelvic surgery, it is important to anticipate potential anatomic variations, which may be unknown, and inter-relationships among intrapelvic vessels. Here, we comprehensively analyzed intrapelvic vessel patterns.

Method: This retrospective analysis included 81 patients that underwent colorectal surgery in our institution in 2016. A total of 162 half-pelvises were imaged with contrast-enhanced computed tomography. We scrutinized thinslice images.

Results: We found variations in the number of internal iliac veins. In $47.5 \%$ of cases, one internal iliac vein drained into the ipsilateral common iliac vein in both halves of the pelvis. In the other cases, several internal iliac veins were observed in one or both halves of the pelvis. We analyzed the inter-relationships between the superior gluteal artery and the sacral nerve plexus in pelvic halves. Superior gluteal arteries ran between the 5th lumbar nerve and 1st sacral nerves, in $82 \%$ of halves, and lateral to the 5 th lumbar nerve, in $17 \%$ of halves. Dorsally, the superior gluteal artery ran on the medial side of the internal iliac vein in $15 \%$ of halves. In $28 \%$ of half-pelvises, two superior gluteal veins were observed. Superior gluteal veins passed through the sacral nerve plexus lateral to 5 th lumbar, between 5th lumbar and 1st sacral, and between 1st and 2nd sacral nerve, in 42.0, 47.5, and 37.7\% of halves, respectively. We evaluated the rate of symmetric pelvic anatomies, and found that all anatomic variations formed symmetrically, except the number of internal iliac veins.

Conclusion: This study clarified the anatomical variations of intrapelvic vessels and their inter-relationships. These findings will benefit our understanding of pelvic anatomy and enhance the safety of radical surgery for treating pelvic diseases.
\end{abstract}

Keywords: Pelvic anatomy, lliac artery, Iliac vein, Rectal cancer

\section{Background}

Many organs and tissues lie in complicated juxtaposition in the pelvic cavity, including vessels, nerves, muscles, urogenital organs, and the rectum. The spatial configurations of these organs are difficult to comprehend for many surgeons. Recent studies have demonstrated that threedimensional models or three-dimensional simulations

\footnotetext{
*Correspondence: ahamabe1981@gmail.com

Department of Surgery, Toyonaka Municipal Hospital, 4-14-1 Shibahara-cho, Toyonaka, Osaka 560-8565, Japan
}

could be helpful in understanding this complexity [1, 2]. In performing advanced surgery for rectal cancer and cancers that arise in urological or gynecological organs, it is necessary to have an accurate, comprehensive understanding of pelvic anatomy to perform safe, oncologically appropriate surgery. However, in addition to the complexity of the pelvic cavity, many anatomical variations, particularly vascular patterns, make it even more difficult to understand. Only a few studies have demonstrated the morphological variability in the courses of the internal

(c) The Author(s). 2020 Open Access This article is licensed under a Creative Commons Attribution 4.0 International License, which permits use, sharing, adaptation, distribution and reproduction in any medium or format, as long as you give appropriate credit to the original author(s) and the source, provide a link to the Creative Commons licence, and indicate if changes were made. The images or other third party material in this article are included in the article's Creative Commons licence, unless indicated otherwise in a credit line to the material. If material is not included in the article's Creative Commons licence and your intended use is not permitted by statutory regulation or exceeds the permitted use, you will need to obtain permission directly from the copyright holder. To view a copy of this licence, visit http://creativecommons.org/licenses/by/4.0/ The Creative Commons Public Domain Dedication waiver (http://creativecommons.org/publicdomain/zero/1.0/) applies to the data made available in this article, unless otherwise stated in a credit line to the data. 
iliac artery, vein, or obturator vessels. Moreover, most of those studies were based on a small series or they addressed the variability of an individual artery or vein [3-9]. During surgery, it is also quite important to understand the inter-relationships between intrapelvic organs, in addition to individual variability, and these issues are rarely studied. Based on this background, the current study was undertaken to provide a comprehensive analysis of intrapelvic vascular anatomic variability, to elucidate the distribution of different pelvic vascular pattern variations, and to determine systematically the interrelationships among intrapelvic vessels.

\section{Methods}

\section{Patients}

This retrospective analysis included 81 patients that underwent colorectal surgery for colorectal cancers in our institution in 2016. These patients had undergone contrast-enhanced computed tomography (CT) in a preoperative work-up. All CT images were acquired with a 64-detector row CT scanner (Revolution GSI and Revolution EVO, GE Healthcare, Milwaukee, WI, USA). The CT scan was started at $70 \mathrm{~s}$ after an injection of nonionic contrast agent with iodine. In our institution, we routinely reconstructed thin-slice CT images $(1.25-\mathrm{mm}$ thick or occasionally $0.625-\mathrm{mm}$ thick) for rectal cancer cases that required lateral pelvic lymph node dissection.

\section{Interpretation of intrapelvic vascular anatomy}

A total of 162 pelvic halves in 81 patients were examined. CT images were interpreted in detail, independently, by two surgeons $\mathrm{AH}$, a specialist in colorectal surgery, and $\mathrm{TH}$ ). In cases of disagreement, the final interpretation was based on a mutual agreement between the two surgeons. After this process, all images were carefully confirmed again (by AH).

We examined the locations of spinal nerves, 5th lumbar nerve (L5), 1st sacral nerve (S1), and 2nd sacral nerve (S2), which join together to form the sacral nerve plexus. We also examined the locations of arteries, including the common, external, and internal iliac arteries (CIA, EIA, and IIA, respectively), the superior and inferior gluteal arteries (SGA and IGA, respectively), and the internal pudendal artery (IPA). We also examined the locations of veins, including the common, external, and internal iliac veins (CIV, EIV, and IIV, respectively), the superior gluteal vein (SGV), and the aberrant obturator vein.

In the current study, variations in the branching pattern of the IIV were classified as follows (Fig. 1): in type I, one IIV drained into the ipsilateral CIV in both halves of the pelvis; in type II, two IIVs drained into the ipsilateral CIV in one or both halves of the pelvis; in type III, one of the two IIVs drained into the contralateral CIV, and the other drained into the ipsilateral CIV; and type IV comprised all variations in IIV patterns that did not fit into types I-III. Additionally, type II was subclassified into three subtypes: in type IIa, two IIVs were present in the left half of the pelvis; in type IIb, two IIVs were present in the right half of the pelvis; and in type IIc, two IIVs were present in both halves of the pelvis. Similarly, type III was classified into two subtypes: in type IIIa, one IIV draining toward the ipsilateral cavity ran from the right cavity into the left CIV; in type IIIb, it ran from the left cavity into the right CIV.

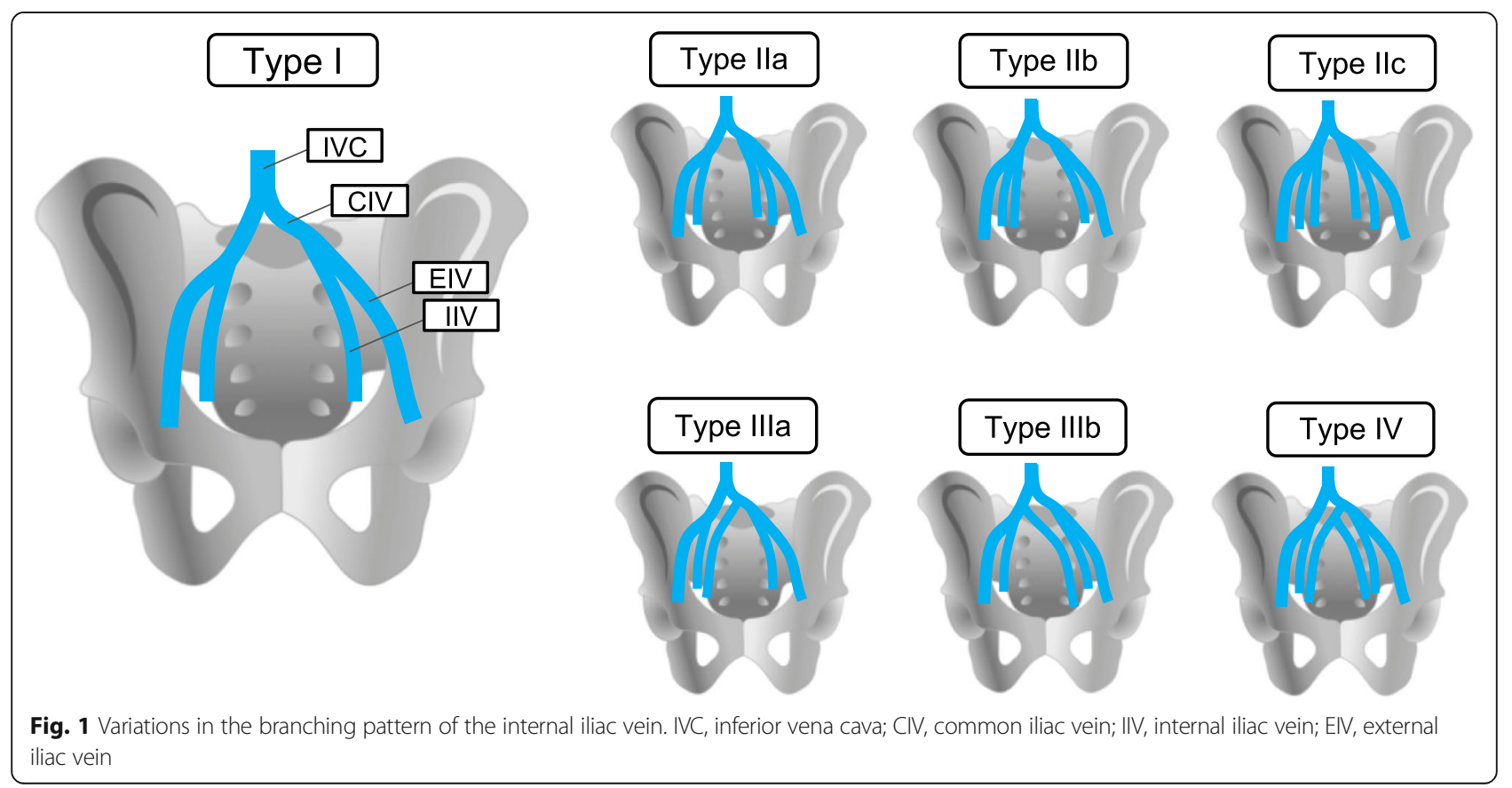




\section{Statistical analysis}

All statistical analyses were performed with JMP pro 13.0.0 software (SAS Institute, Cary, NC, USA). A kappa score was calculated to evaluate whether the pelvic anatomy was symmetric.

\section{Results}

\section{Patient background}

The cohort of 81 patients included 42 (51.9\%) males and $39(48.1 \%)$ females, with a median age of 73 years (range 40 to 84 years). The primary tumors were located in the right-side colon (from the cecum to the transverse colon) in 19 patients (23.5\%); in the left-side colon (from the descending to the sigmoid colon) in 30 patients (37.0\%); and in the rectum in 32 patients (39.5\%). CT slices were $0.675-\mathrm{mm}$ thick in 7 cases $(8.6 \%)$ and 1.25 $\mathrm{mm}$ thick in 74 cases $(91.4 \%)$.

\section{Internal iliac vein}

The vascular branching pattern variations observed in the IIV are shown in Fig. 1 (details in Table 1). The type I branching pattern was observed in $47.5 \%$ of all cases. The other cases had several IIVs in one or both halves. Types II and III branching patterns were observed in about 40 and $10 \%$ of all cases, respectively. Among 10 cases of type III, 9 were type IIIa. One case of type IV was observed, where two IIVs were present on both sides, and two medial IIVs joined together in front of the sacrum, then drained into the left CIV.

\section{Inter-relationships between the sacral nerve plexus and superior gluteal vessels}

On each side of the pelvis, there are four routes for vessels to exit out of pelvis formed by the L5, S1, and S2 spinal nerve branches. The vascular branches of the internal iliac vessels must negotiate these routes as they pass out of the pelvis. We examined the interrelationships between these routes and the SGA. We found that $82 \%$ of SGAs ran between the L5 and S1 branches, and $17 \%$ of SGAs ran lateral to the L5 branch (Fig. 2, upper panel; Table 1). Similarly, we analyzed the inter-relationships between the routes and the SGV. In $28 \%$ of pelvic halves, two SGVs were observed; therefore, the route through which each SGV passed was evaluated independently (Fig. 2, lower panel; Table 1). We found that the SGVs passed through the routes lateral to L5, between the L5 and S1, and between the S1 and S2 in $42.0,47.5$, and $37.7 \%$ of the halves, respectively.

Inter-relationships among superior gluteal artery, internal iliac artery, and internal iliac vein

We investigated the inter-relationships among the SGA, IIA, and IIV (Fig. 3). The SGA ran dorsally, on the lateral side of the IIV in $85 \%$ of all pelvic halves. In the
Table 1 Vascular pattern variability in the pelvis

\begin{tabular}{|c|c|c|c|}
\hline Analyzed variations & Types & $\begin{array}{l}\text { Number of } \\
\text { patients }\end{array}$ & $\%$ \\
\hline \multirow{7}{*}{$\begin{array}{l}\text { Branching pattern of internal } \\
\text { iliac vein }{ }^{a}\end{array}$} & I & 39 & $48.1 \%$ \\
\hline & Ila & 11 & $13.6 \%$ \\
\hline & $11 \mathrm{~b}$ & 13 & $16.0 \%$ \\
\hline & $\| c$ & 7 & $8.6 \%$ \\
\hline & Illa & 9 & $11.1 \%$ \\
\hline & $\| l \mid b$ & 1 & $1.2 \%$ \\
\hline & IV & 1 & $1.2 \%$ \\
\hline Analyzed variations & Types & $\begin{array}{l}\text { Number of } \\
\text { pelvic } \\
\text { halves }^{c}\end{array}$ & $\%$ \\
\hline \multirow{3}{*}{$\begin{array}{l}\text { Section of the route in sacral } \\
\text { nerve plexus, through which } \\
\text { the SGA passes }\end{array}$} & Lateral to $\mathrm{L} 5$ & 27 & $16.7 \%$ \\
\hline & L5-S1 & 133 & $82.1 \%$ \\
\hline & S1-S2 & 2 & $1.2 \%$ \\
\hline \multirow{4}{*}{$\begin{array}{l}\text { Section of the route in sacral } \\
\text { nerve plexus, through which the } \\
\text { SGV passes }\end{array}$} & Lateral to $\mathrm{L} 5$ & 68 & $42.0 \%$ \\
\hline & L5-S1 & 77 & $47.5 \%$ \\
\hline & S1-S2 & 61 & $37.7 \%$ \\
\hline & Medial to S2 & 2 & $1.2 \%$ \\
\hline \multirow{4}{*}{$\begin{array}{l}\text { Inter-relationship between the } \\
\text { IGA and the IPA at the exit of } \\
\text { the pelvis }\end{array}$} & $\begin{array}{l}\text { IGA medial } \\
\text { and IPA lateral }\end{array}$ & 104 & $64.2 \%$ \\
\hline & $\begin{array}{l}\text { IGA lateral and } \\
\text { IPA medial }\end{array}$ & 13 & $8.0 \%$ \\
\hline & $\begin{array}{l}\text { IGA and IPA as } \\
\text { a common } \\
\text { trunk }\end{array}$ & 19 & $11.7 \%$ \\
\hline & Others & 26 & $16.0 \%$ \\
\hline \multirow[t]{2}{*}{ Aberrant obturator vein } & Present & 114 & $70.4 \%$ \\
\hline & Absent & 48 & $29.6 \%$ \\
\hline
\end{tabular}

${ }^{\mathrm{a}}$ These patterns are illustrated in Fig. 1. ${ }^{\mathrm{b}}$ These patterns are illustrated in Fig. 2. 'In some cases, two SGVs were found in a single pelvic half; therefore, the total number in that section exceeds the 162 pelvic halves, and the percentage exceeds $100 \%$. IGA Inferior gluteal artery, IPA Internal pudendal artery, $L 5$ 5th lumbar nerve, $S 1$ 1st sacral nerve, $S 2$ 2nd sacral nerve, SGA Superior gluteal artery; SGV, superior gluteal vein

remaining $15 \%$ of pelvic halves, the SGA ran dorsally, on the medial side of the IIV (Fig. 3a, b and c).

\section{Unique variation}

Fifteen pelvic halves showed a unique pattern in the inter-relationship between IIA and IIV (Fig. 4a and b). In these halves, two IIVs intercommunicated with each other, and thus, they formed a venous loop in front of the sacral nerve plexus. The SGA passed through this loop, and then ran dorsally, toward the buttock.

\section{Vascular variations in lateral cavities}

Furthermore, we investigated additional variations, including the inter-relationship between the IGA and IPA, at the level of the pelvic outlet, and the presence of an aberrant obturator vein (Table 1). About $70 \%$ of the IIAs 


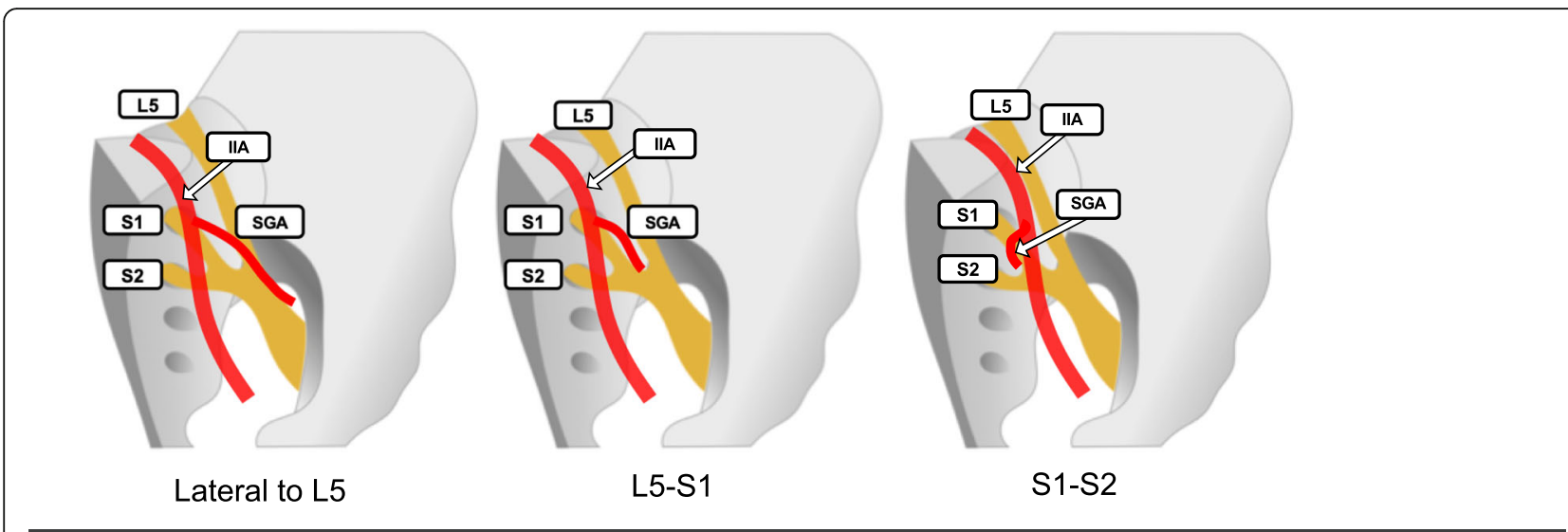

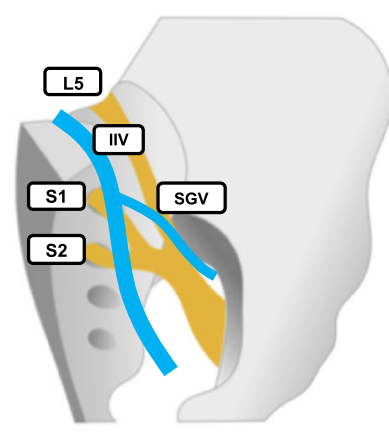

Lateral to L5

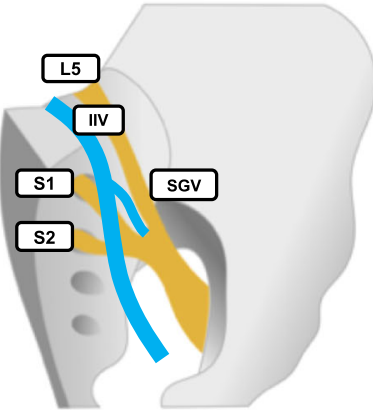

L5-S1

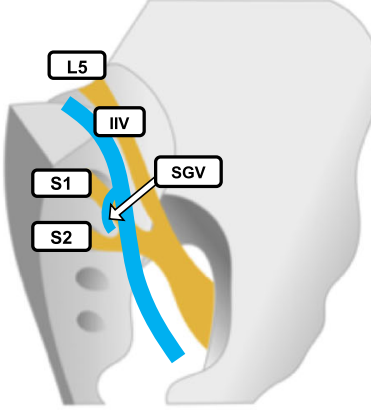

S1-S2

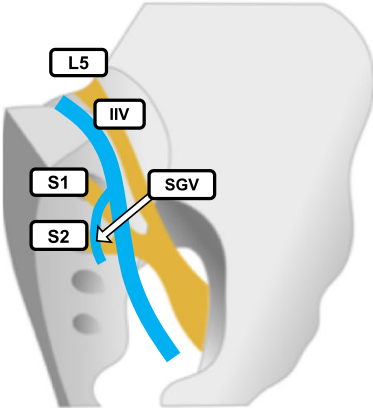

Medial to S2

Fig. 2 Variations in inter-relationships between the spinal nerves and the superior gluteal artery and vein. (Upper panel) Patterns of the superior gluteal artery (SGA). (Lower panel) Patterns of the superior gluteal vein (SGV). IIA, internal iliac artery IIV, internal iliac vein; L5, 5th lumbar nerve; S1, 1st sacral nerve; S2, 2nd sacral nerve

(a)

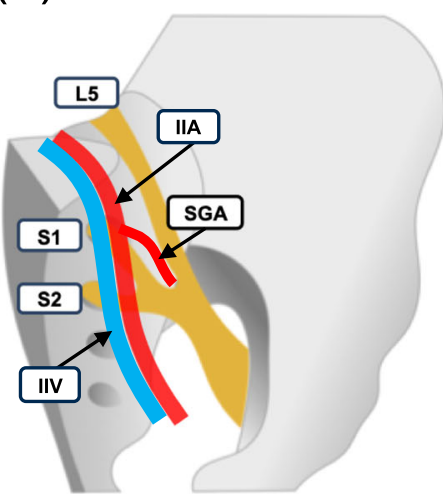

(b)

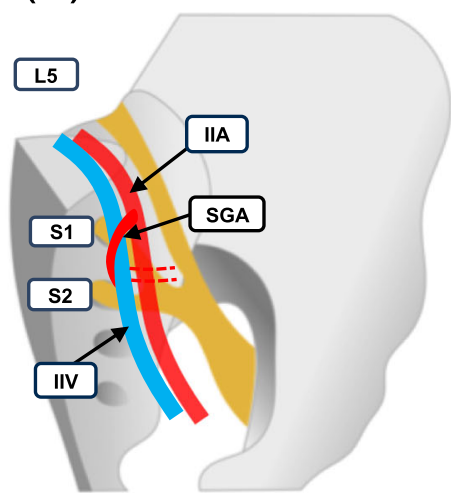

(c)

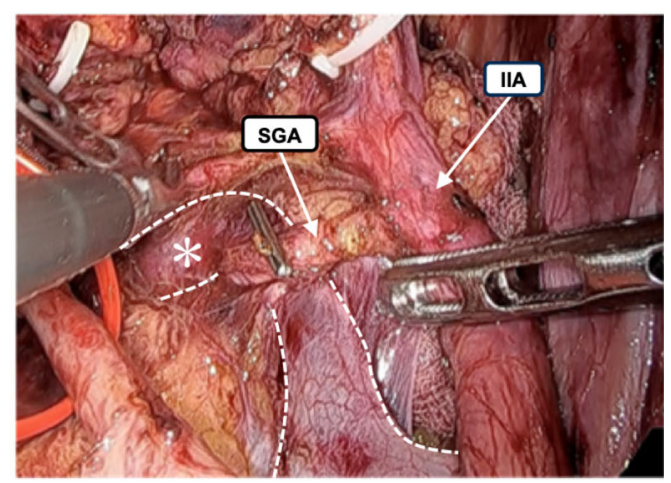

Fig. 3 Inter-relationships among the superior gluteal artery (SGA) and the internal iliac artery and vein. (a) The SGA (red) runs dorsal, on the lateral side of the internal iliac vein (blue). (b) The SGA runs dorsal, on the medial side of the internal iliac vein. (c) Representative photograph of the right side of the pelvic cavity, which shows the pattern described in (b). Photograph was acquired during laparoscopic surgery for a lateral lymph node dissection. Asterisk (*) represents the internal iliac vein. IIA, internal iliac artery IIV, internal iliac vein; L5, 5th lumbar nerve; S1, 1st sacral nerve; S2, 2nd sacral nerve; SGA, superior gluteal artery 
(a)

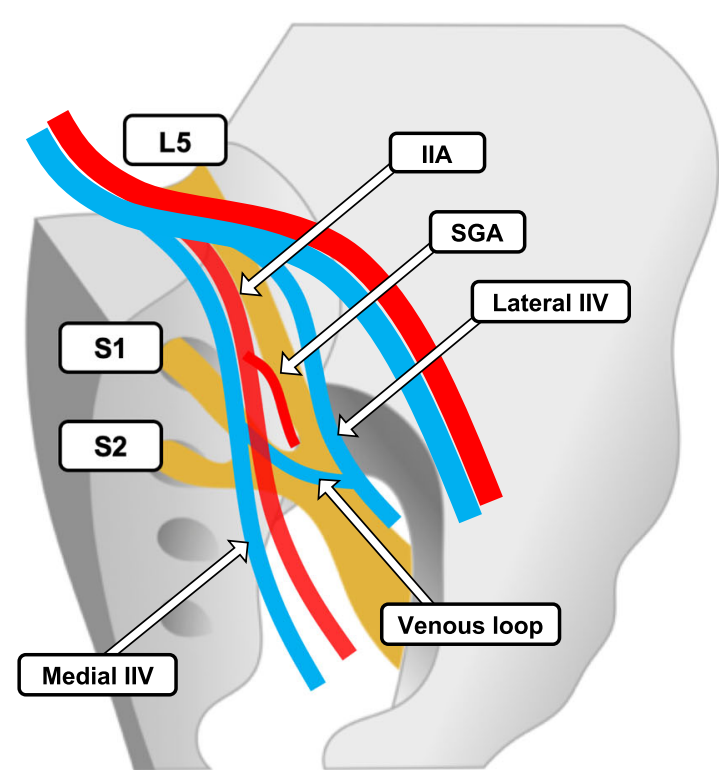

(b)

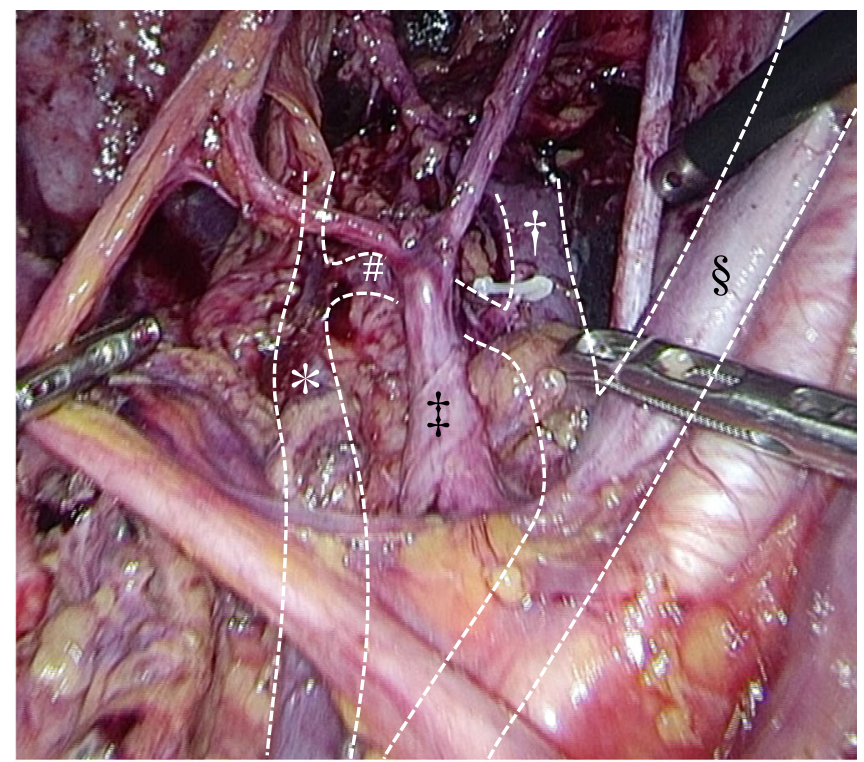

Fig. 4 A unique variation of the inter-relationship between the internal iliac artery (IIA) and vein (IIV). (a) The schematic figure illustrates this pattern. (b) Representative intra-operative photograph shows this pattern on the right side of the pelvic cavity. Photograph was acquired during laparoscopic surgery for a lateral lymph node dissection. Asterisk $\left(^{*}\right)$ represents the medial internal iliac vein (IIV); dagger $\left(^{\dagger}\right)$ represents the lateral IIV; double dagger $\left({ }^{\ddagger}\right)$ represents the internal iliac artery (IIA); hash sign $\left(^{\#}\right)$ represents the venous loop between the two IIVs, which has formed in front of the sacral nerve plexus; and the section sign $\left(^{\S}\right)$ represents the external iliac vein. IIA, internal iliac artery IIV, internal iliac vein; L5, 5th lumbar nerve; S1, 1st sacral nerve; S2, 2nd sacral nerve; SGA, superior gluteal artery

divided into IPA and IGA branches in the pelvic cavity. In $12 \%$ of the pelvic halves, the IIAs passed out of pelvis as a common trunk. In pelvic halves where IPA and IGA were divided in pelvic cavity, the IGA exited the pelvis on the medial side more frequently than on the lateral side of the IPA. The remaining cases had other types of IIA divisions; for example, sometimes, the IGA branched off the SGA outside the pelvis and ran toward the buttock. An aberrant obturator vein was present in $70 \%$ of pelvic halves.

\section{Anatomic symmetry in the lateral pelvic cavities}

The rate of pelvic anatomic symmetry, or the concordance rate of pelvic anatomies, was analyzed for the following variations; the route that the SGA passed through; a SGA that ran dorsally, on the medial side of the IIV; the number of SGVs; the route that the SGV passed through; the presence of an aberrant obturator vein; and the number of IIVs (Table 2). We found that all anatomical variations, other than the number of IIVs, were symmetric.

\section{Discussion}

This study revealed details about the inter-relationships among pelvic vessels and their anatomic variations in pelvic cavity. Furthermore, several unique anatomical variations were observed in a few cases. This study was the first to elucidate these patterns, and our findings have important implications for surgeons.

Since Adachi first classified the IIA branching variations into five types [3], several studies have investigated the distributions of branching patterns in different populations [4-6]. Although those studies analyzed arterial variations in detail, they only assessed the IIA, independent of other vessels. Information other than arterial variations have not been available, due to the scarcity of studies that investigated vein, muscle, or nerve anatomies. Therefore, the present study addressed the unmet need for a comprehensive analysis of pelvic vascular anatomy, including anatomic inter-relationships and variations.

Current textbooks on human anatomy illustrate intrapelvic vessels and their inter-relationships as invariant $[10,11]$. Typically, the SGA branches off the IIA, runs posteriorly, on the lateral side of the IIV, passes between the L5 and S1 nerves, and runs toward the buttock. In addition, the IIV branches off the CIV, one on each side. Many surgeons probably consider this configuration to be typical pelvic anatomy, and they might implement surgery based on that assumption. However, the present study demonstrated that not all pelvic vessels form those stereotypic patterns. In locally recurrent rectal cancer 
Table 2 Anatomic symmetry in the lateral cavities of the pelvis

\begin{tabular}{|c|c|c|c|}
\hline Analyzed variations & Concordance rate & Kappa & $\boldsymbol{P}$ value \\
\hline The route where the SGA passes through & $77.8 \%$ & 0.26 & 0.0069 \\
\hline SGA runs dorsally, on the medial side of the IIV & $84.0 \%$ & 0.39 & $<0.0001$ \\
\hline The number of SGVs & $70.4 \%$ & 0.28 & 0.0057 \\
\hline The SGV passes lateral to $L 5$ & $75.3 \%$ & 0.49 & $<0.0001$ \\
\hline The SGV passes between $L 5$ and S1 & $71.6 \%$ & 0.43 & $<0.0001$ \\
\hline The SGV passes between S1 and S2 & $74.1 \%$ & 0.45 & $<0.0001$ \\
\hline The SGV passes medial to S2 & $100.0 \%$ & 1 & $<0.0001$ \\
\hline The presence of an aberrant obturator vein & $76.5 \%$ & 0.45 & $<0.0001$ \\
\hline The number of IIVs & $61.7 \%$ & 0.13 & 0.1061 \\
\hline
\end{tabular}

IIV Internal iliac vein, L5 5th lumbar nerve, S1 1st sacral nerve, S2 2nd sacral nerve, SGA Superior gluteal artery, SGV Superior gluteal vein

treatments, surgical resection is one of the options for cure, in which we must perform radical surgery with en bloc resection with involved surrounding organs including internal iliac vessels to achieve tumor-free resection [12-14]. Understanding the above vascular variations might be valuable to prevent inadvertent intraoperative bleeding from the internal iliac vessels in such advanced surgeries.

In our opinion, some of the facts clarified in this study are quite noteworthy. First, we described the anatomic inter-relationships around the IIA. Although the SGA branches off the IIA and typically passes through the L5S1 split, 17\% of SGAs run in front of L5 and pass lateral to L5. In addition, in some cases, the SGA runs dorsally, on the medial side of the IIV. These uncommon variations should be recognized preoperatively to prevent unexpected vascular injury, which might lead to severe outcomes. For example, lateral lymph node dissection is needed to resect advanced rectal cancer with metastatic lateral node $[15,16]$. During this procedure, lymph nodes around IIVs are included in the dissected area, and therefore we must pay attention to the SGA running on the medial side of the IIV which was found to be observed in $15 \%$ of pelvic halves. Second, we found that pelvic anatomy was formed symmetrically. This finding suggested that, although many anatomic variations are present in the pelvis, pelvic anatomies are not likely to arise at random. These facts might facilitate the evaluation and detection of anatomic variations in the pelvis with more precision, in advance of surgery.

Although most preceding studies were based on cadaver inspections, in this study, we assessed contrastenhanced CT images. In cadaver inspection, after dissecting the anatomic structures, it is not necessarily simple to determine the original structure. The procedure might also obscure anatomic inter-relationships. Furthermore, recent advances in CT technology have allowed clear depictions of anatomic structures even when they were covered with visceral fat. Several studies that analyzed abdominal vascular anatomy also adopted CT for making assessments $[17,18]$.

This study had several limitations. First, the retrospective study design had inherent limitations. In particular, our findings could not be confirmed intraoperatively. Second, the CT scans were performed once in the portal phase; this technique could have obscured the depiction of some individual vessels. Ideally, both arterial and venous phases should be obtained.

\section{Conclusions}

This study clarified the anatomic variations and interrelationships of pelvic vessels in detail. We found some rare patterns, which should be considered during surgery. These findings will benefit our understanding of pelvic anatomy and enhance safety in performing radical surgery for treating pelvic diseases.

\section{Abbreviations}

CIA: Common iliac artery; CIV: Common iliac vein; CT: Computed tomography; EIA: External iliac artery; EIV: External iliac vein; IGA: Inferior gluteal artery; IIA: Internal iliac artery; IIV: Internal iliac vein; IPA: Internal pudendal artery; IVC: Inferior vena cava; L5: 5th lumbar nerve; S1: 1st sacral nerve; S2: 2nd sacral nerve; SGA: Superior gluteal artery; SGV: Superior gluteal vein

\section{Acknowledgements \\ None.}

\section{Competing interest}

The authors declare no conflict of interest.

\section{Disclosures}

Atsushi Hamabe, Takashi Harino, Takayuki Ogino, MD, Tsukasa Tanida, Shingo Noura, Shunji Morita, and Keizo Dono have no conflicts of interest or financial ties to disclosure regarding this study.

Authors' contributions

All authors have read and approved the manuscript. Study concept and design: $\mathrm{AH}, \mathrm{SN}$ and SM. Data collection: $\mathrm{AH}$ and TH. Data analysis and interpretation: $A H, T H, T O, T T, S N, S M$ and $K D$.

Funding

This study received no funding. 


\section{Availability of data and materials}

The datasets used and/or analyzed during the current study are available from the corresponding author on reasonable request.

\section{Ethics approval and consent to participate}

All procedures performed in studies involving human participants were in accordance with the ethical standards of the institutional and/or national research committee and with the 1964 Declaration of Helsinki and its later amendments or comparable ethical standards. This study was approved by the institutional Ethics Committee in Toyonaka Municipal Hospital, and a written informed consent was obtained from all individual participants before surgery for collection and analysis of the data. This article does not contain any studies with animals performed by any of the authors.

\section{Consent for publication}

Not applicable.

\section{Competing interests}

The authors declare that they have no competing interests.

Received: 15 December 2019 Accepted: 5 March 2020

Published online: 16 March 2020

\section{References}

1. Sora MC, Jilavu R, Matusz P. Computer aided three-dimensional reconstruction and modeling of the pelvis, by using plastinated cross sections, as a powerful tool for morphological investigations. Surg Radiol Anat. 2012;34:731-6.

2. Hamabe A, Ito M. A three-dimensional pelvic model made with a threedimensional printer: applications for laparoscopic surgery to treat rectal cancer. Tech Coloproctol. 2017;21:383-7.

3. Watanabe K, Shoja MM, Loukas M, et al. Buntaro Adachi (1865-1945): Japanese master of human anatomic variation. Clin Anat. 2012;25:957-60.

4. Braithwaite JL. Variations in origin of the parietal branches of the internal iliac artery. J Anat. 1952;86:423-30.

5. Roberts $W H$, Krishingner GL. Comparative study of human internal iliac artery based on Adachi classification. Anat Rec. 1967;158:191-6.

6. Sakthivelavan S, Aristotle S, Sivanandan A, et al. Variability in the branching pattern of the internal iliac artery in Indian population and its clinical importance. Anat Res Int. 2014;2014:597103.

7. Krishnamurthy A, Nayak SR, Khan S, et al. Anomalous channels draining the internal iliac veins: embryological and clinical significance. Rom J Morphol Embryol. 2007:48:71-3

8. Oto A, Akpinar E, Surucu HS, et al. Right internal iliac vein joining the left common iliac vein: case report demonstrated by CT angiography. Surg Radiol Anat. 2003;25:339-41.

9. Lotz PR, Seeger JF. Normal variations in iliac venous anatomy. AJR Am J Roentgenol. 1982;138:735-8.

10. Netter F. Atlas of human anatomy. 7th ed. Amsterdam: Elsevier; 2018.

11. Agur AMR, Dalley AF. Grant's Atlas of Anatomy. 13th ed. Philadelphia: Lippincott Williams \& Wilkins; 2012.

12. Alberda WJ, Verhoef C, Schipper ME, et al. The importance of a minimal tumor-free resection margin in locally recurrent rectal Cancer. Dis Colon Rectum. 2015;58:677-85.

13. Mirnezami AH, Sagar PM, Kavanagh D, Witherspoon P, Lee P, Winter D. Clinical algorithms for the surgical management of locally recurrent rectal cancer. Dis Colon Rectum. 2010;53:1248-57.

14. Troja A, El-Sourani N, Abdou A, Antolovic D, Raab HR. Surgical options for locally recurrent rectal cancer--review and update. Int J Colorectal Dis. 2015; 30:1157-63.

15. Kim TG, Park W, Choi DH, et al. Factors associated with lateral pelvic recurrence after curative resection following neoadjuvant chemoradiotherapy in rectal cancer patients. Int J Colorectal Dis. 2014;29: $193-200$.

16. Kusters $M$, Slater $A$, Muirhead $R$, et al. What to do with lateral nodal disease in low locally advanced rectal Cancer? A call for further reflection and research. Dis Colon Rectum. 2017:60:577-85.

17. Ogino T, Takemasa I, Horitsugi G, et al. Preoperative evaluation of venous anatomy in laparoscopic complete mesocolic excision for right colon cancer. Ann Surg Oncol. 2014;21(Suppl 3):S429-35.
18. Hamabe A, Park S, Morita S, et al. Analysis of the vascular interrelationships among the first Jejunal vein, the superior mesenteric artery, and the middle colic artery. Ann Surg Oncol. 2018;25:1661-7.

\section{Publisher's Note}

Springer Nature remains neutral with regard to jurisdictional claims in published maps and institutional affiliations.
Ready to submit your research? Choose BMC and benefit from:

- fast, convenient online submission

- thorough peer review by experienced researchers in your field

- rapid publication on acceptance

- support for research data, including large and complex data types

- gold Open Access which fosters wider collaboration and increased citations

- maximum visibility for your research: over $100 \mathrm{M}$ website views per year

At BMC, research is always in progress.

Learn more biomedcentral.com/submissions 